\title{
Exploration and Analysis on "Graphic Design" Course Teaching Reform in Vocational Colleges
}

\author{
Huang keqin ${ }^{1,}$, \\ ${ }^{1}$ Chongqinq College of Electronic Engineering, Faculty of Art Media,Chongqing,401331,China \\ ahkqin@126.com
}

Keywords: Exploration, Analysis, "Graphic Design", Course Teaching Reform, Vocational Colleges

\begin{abstract}
With the expansion of the social needs of graphic design professionals, more and more Vocational Colleges set the profession of graphic design, and graphic design curriculum is very important. However, currently there are some problems in graphic design base curriculum such as old ideas, old teaching methods, the resource of teachers is weak, curriculum system is imperfect, and the low quality of students and other issues.
\end{abstract}

\section{Introduction}

With the rapid development in recent years, China's economic construction, graphic design professionals demand also will become increasingly strong, so widespread in China Vocational College have opened graphic design, however, there are many vocational colleges only focus on expanding the number of enrollment and school size, and in terms of teaching programs, teaching mode, teaching methods and teaching facilities and the work put into the very lack of such graphic design of the actual teaching effect of greatly reduced, resulting in overall quality of students graduating lack of capacity, the prevalence of a solid foundation of professional knowledge, practical ability is not strong and other issues, out of touch with the real needs of society. In addition, the graphic design is one pair of students' practical ability is very high professional, so increase the proportion of practice teaching, students master practical skills in print ads designed to help students be successful employment Vocational Colleges Graphic Design the main purpose. Therefore, higher vocational colleges need to graphic design and usability features hands-on ability to adjust and reform the teaching content and teaching methods, in particular, to improve the training of teaching more and more important position, because to build a Higher Colleges of scientific and effective graphic design training teaching quality assurance and monitoring system is to help students to integrate theory with practice, effective way to improve students' practical ability, but also has an important part of culture innovative high-quality talent, but also for protection of the quality of teaching, standardized teaching management, also have a significant practical significance. Currently, training teaching graphic design has become higher vocational colleges teaching the weakest link, but there are many problems in the process of teaching specific, so this paper plane design higher vocational colleges teaching professional characteristics and training objectives, the status quo at this stage of graphic design Higher Colleges practice training a brief introduction, but also analyzed and discussed the future trends of graphic design, as well as how to promote design training plane Vocational Colleges Teaching.

In order to meet the inherent requirements of the rapid development of the market economy, the Higher Colleges of graphic design talent must have a strong creative thinking ability and keen market development potential, the only way to meet the needs of the knowledge economy era, from this perspective dealing with current higher vocational colleges teaching graphic design it is necessary to reform the traditional fall backward teaching ideas and teaching mode, to be able to cultivate adapt to the economic development requirements of the current talent.

\section{The Problems of the Graphic Design Basis Curriculum}

Graphic Design Curriculum Doesn't Get Enough Attention. With society constantly improve the quality of talent requirements, some of the higher vocational colleges began working to develop 
students' professional skills, set up a large number of computer software programs such as Photoshop, Corel DRAW, etc., accounted for most of the students learning time. Some Vocational Colleges in graphic design only concerned about students to master the skills of skilled software, do not realize the importance of graphic design foundation courses in order to adapt to work after graduation working for some time. Some students in learning computer software programs and there is no solid basic knowledge of drawing, color, graphic composition, color composition, graphic design, art appreciation courses and other basic lack of systematic and thorough research. Some colleges even canceled some of the graphic design curriculum teaching, such as art appreciation lessons that students learn skills and find a job does not require such a course. Some institutions and students do not pay attention to graphic design foundation course, this situation needs to change. Only teachers recognize the importance of graphic design curriculum in order to continuously improve their level of knowledge, so as to enhance the quality of teaching.

The Curriculum System Is Imperfect. Some courses in higher techs system is not perfect, school or faculty leadership is not graphic design background, the entire professional training program are not familiar with, the more clear when implemented, simply that the students in the first year of completion All graphic design foundation course it does not consider graphic design curriculum schedule time and backward and forward linkages, do not know how a ring connected to a ring to convergence in place, not solved graphic design basal course teaching problems, making Graphic design curriculum is too shallow, causing students can not scientifically and effectively learn basic graphic design knowledge and expertise. Graphic design is a basic course additional graphic design Course prerequisite is also the foundation of student learning, the teaching effect plays a key role.

The Resource of Teachers Is Weak. Graphic Design rise in China relatively late, a number of vocational colleges let the computer professional teachers and fine arts teachers to assume the task of teaching graphic design, professional counterparts do not directly affect the effectiveness of teaching. These teachers often just theory to explain verbally, the lack of practical experience in advertising graphic design, teaching feeble, unconvincing, but also the lack of actual advertising business interpretation, students trained is likely to occur advertising market demand analysis is not in place advertising investigation is not in place, unable to adapt to social development issues. Graphic Design Foundation Course teaching effectiveness and classroom teachers' attitudes and teaching methods have great relevance. Some teaching methods are simple, old, do not understand the cultural background of the work.

The Low Quality of Students. First, some of the basic skills of students is not solid. With the continuous advance of China's education reform, expanding school enrollment, enrollment threshold is not high art students, admission is low, some students lack basic skills training system, does not have the artistic talent. Some students enter the university due to the change in the learning environment, learning tasks are arduous, but also participate in various activities, lack of basic skills training to strengthen.

Second, some students' cultural awareness is not high. Teaching is one of the factors most basic literacy students. For various reasons, some of the students' cultural level is not high, weak ability to understand, with contempt in the concept of cultural accumulation, leading to low literacy. So, some students cannot be the perfect combination of skill and art, poor sense of art, professional foundation is weak, lack of motivation, lack of self-confidence. These issues affect the enthusiasm of these students, their ability to innovate and inspire not culture. It also created obstacles for teachers teaching and upgrade the students' later professional level

\section{The Necessity Analysis of Graphic Design Education Reform in Vocational Colleges}

Although since 1998, the Ministry of Education formally classified art graphic design education to professional art and design disciplines, but in higher vocational and technical colleges of art education in graphic design is quite late, there is still a lot of outstanding issues, which problems need to be reformed as soon as possible. These problems are mainly in the following aspects: First, still using backward teaching methods, chalk and talk teaching mode has also been widely used, this 
mode of teaching so that students can easily lose the initiative thinking and behavior, not to mention the sense of innovation culture ; the second is the school's graphic design teaching touch with social needs serious, graphic design teaching in higher vocational colleges and research because of the shortage of teachers, coupled with professional teachers for market research is too small, cannot put their teaching with the market demand linked, so students out of education simply cannot meet the requirements of employers; Third, students' learning attitude is not correct, many of the students of Polytechnic and studied graphic design at the time, only passive learning, the purpose is simply passed the examination, such learning attitude seriously affected the effectiveness of teaching graphic design; Fourth, over-reliance on the teaching of computer design, with the development of computers and other high-tech, graphic design teaching can make use of the medium of instruction is also rich, if a teacher in the teaching of graphic design We cannot reasonably use computer software not only receive less than ideal teaching effect, but will have the opposite effect; Fifth, the students' practical and innovative ability lack, less graphic design class teaching curriculum, but teaching task is very heavy. Under such circumstances it is easy to neglect teaching students practical ability and creative ability, but only taught the students some of the clutter of so-called knowledge, not to give students the opportunity to design practice and training, in fact, graphic design is a very capable hands discipline, the teacher must explain the same opportunity to give students hands-on practice and, in practice, can only innovation. In view of the many outstanding problems in teaching graphic design over Vocational Colleges have a serious impact on the current teaching graphic design effects, from this perspective, the current higher vocational colleges teaching graphic design it is necessary to reform the traditional fall backward and teaching philosophy teaching mode, to be able to cultivate adapt to the economic development requirements of the current graphic design talent.

\section{The Measures Exploration of Graphic Design Teaching Reform in Vocational College}

Focus on teaching design theory and comprehensive teaching, training students' comprehensive thinking and overall quality. First, graphic design teaching must be to highlight the overall concept and comprehensive thinking, teachers need to constantly update the concepts of education, and constantly improve their own knowledge structure, develop their own practical experience, because of lack of knowledge and innovation is unable engaged in this highly specialized course teaching. Secondly, the Higher Colleges of graphic design talent needs to be comprehensive talent, then at the same time focusing on skills development must be to strengthen the overall quality of students, to carry out various forms of educational activities, in order to broaden their horizons and vision. This requires usually pay attention to students' comprehensive quality in all aspects, require students to learn more than the professional graphic design but also to learn literature, philosophy and the arts, but also better able to relate to marketing and consumer psychology and other disciplines of knowledge . Finally, graphic design teaching should always strengthen ties with the community of students, out of school to give students the opportunity to get to know their own design collection and proposition relevant market information element, for allowing students in the school will be able to familiarity and substantial design tasks independently.

Focus on training students' innovative personality style and design. First, the essence of the design is to create, and the need to create the designer's creative thinking. Designer's creative thinking from their individual differences and insights. So graphic design teaching must attach great importance to students of design creativity and personalized design style, teachers should encourage students to bold imagination, students personalized thinking, and fully tap the potential of each person's creative thinking, so design was more distinctive and unique personality, the students trained only have personality and innovation. Secondly, since the 80 s of the last century with the advent of computer graphic design bring unprecedented change, although this improves the efficiency of the process and the work of designers from the plane to a certain extent, but also to the current graphic design teaching when posed a serious challenge, so teaching graphic design in order to calmly deal with the pressures of high-tech and the rapid development of the business environment, it is necessary to design creative must have a personality, graphic design teachers to 
focus on teaching students design creative expression of personal, fully tap their inner personality styles and potential innovation.

Adjust the curriculum and syllabuses under the Occupational Qualifications. Graphic design curriculum and syllabus of vocational colleges must be based on curriculum objectives as the basis, according to the occupational status of knowledge and ability requirements, so enough theoretical knowledge, professional knowledge and advanced practical, while highlighting the technical application ability, the key is to develop students' practical ability. Also by teaching computer-aided design, so that students can skillfully use computer-aided design in order to meet the development needs of the talent market.

Pay attention to the practice of accumulated experience of students and enhance students' practical ability. First, graphic design is absolutely cannot ignore the students usually experience accumulated, if students lack of understanding of society and business, according to the social and business needs cannot build their own knowledge structure would not meet the current needs of the market. So to take full advantage of their leisure time using a variety of approaches to training students design capabilities, in order to learn from the accumulation of practical experience. Second, we must actively explore diversified and multi-level teaching mode as much as possible organize the students to graphic design practice, so that students can basically stand-alone systems to complete graphic design cases.

On the assessment methods, we have reduced the theory test, mainly works assessment, which allows students to integrate the knowledge and skills, to form the corresponding learning works. On evaluation methods, we mainly use student self-assessment, peer assessment and teacher evaluation group multiple evaluation ways of combining, which emphasizes the active participation of students and mutual evaluation. First, let students work in class multimedia electronic display in the classroom, explain the reasons and design characteristics of the works, it works to make self-evaluation. Then by the students to express their views within the group where the student, while students within the group will work in groups peer assessment. For some of the best student work, we have it posted on the website of teaching, let the students participate in the voting and selection together.

\section{Conclusion}

In short, the foundation courses and teaching of graphic design in vocational college must start from the reality of schools, teachers should strive to overcome the problems, conducting research in terms of the concept of thinking, teaching curriculum, faculty and teaching methods and strive to cultivate students' creative thinking and improve their design level.

\section{References}

[1] Huifang Zhou: Art and Design, Vol. 6 (2014) No 53, p.25-26

[2] Hongli Zhang: Education Article, Vol. 12 (2015) No 27, p.74-76

[3] Qin Guo: Education Guide, Vol. 1 (2016) No 33, p.11-14

[4] Jieming Liu: Management Observation, Vol. 3 (2011) No33, p.121-124

[5] Yang Haiyun: Hunan Normal University, Vol. 1 (2010) No 33, p.121-124 